\title{
Medical Assistance in Dying: A Gendered Issue in Canada?
}

\author{
Freya Hammond-Thrasher \\ Department of Sociology, University of Alberta, Edmonton, Alberta \\ Corresponding author: freyaht@gmail.com
}

\section{ABSTRACT}

Medical assistance in dying (MAiD) remains a controversial topic in Canada despite its legalization in 2015. Opponents of MAiD legislation often cite 'pro-life' or 'pro-choice' arguments which emphasize the value of human life. While all eligible adults are currently able to request MAiD, scholars, citizens, and religious organizations have expressed concerns that women, as a marginalized group, are at risk to request assisted dying due to gendered circumstances rather than personal choice. My research investigates the claim that women's lives are threatened by MAiD legislation and analyzes the ways in which MAiD is a gendered issue. Drawing from seventeen academic, government, and grey literature sources, I identify and challenge three key discursive categories used to present women as vulnerable under MAiD legislation. I argue that opponents of MAiD legislation co-opt feminist discourses to make normative claims which resonate with the values of individualism in Canadian liberal democratic society. In doing so, opponents of MAiD reproduce the same gender issues they claim to oppose and risk endangering women's access to MAiD in Canada. I conclude with recommendations relevant to the next stage of MAiD legislation in Canada, which will debate whether other populations considered to be vulnerable, including mature minors and people with mental illness, will have access to MAiD.

\section{Introductions}

In 2015, the Supreme Court of Canada ruled that the prohibition of medically assisted dying contradicted the Canadian Charter of Rights and Freedoms. One year later, parliament legalized medical assistance in dying (MAiD), allowing adult Canadians with a "grievous and irremediable medical condition" (Government of Canada 2020a) to request a hastened death and physicians and nurse practitioners to provide MAiD without being criminalized. ${ }^{1}$ While all eligible adults are currently able to request MAiD, scholars, citizens, and religious organizations have expressed concerns that women, as a marginalized group, are at risk to request assisted dying due to gendered circumstances rather than personal choice. These arguments tend to focus on three discursive categories which undermine the autonomy of women to choose MAiD for themselves: sociodemographic characteristics of women, such as fewer economic resources; gender roles, such as the valorization of women's self-sacrifice; and power relationships, such as the unequal power dynamic between female patients and physicians who are often men. In this paper, I investigate MAiD as a gendered issue. I argue that opponents of MAiD legislation co-opt feminist discourses to make normative claims which reso-

SPECTRUM | INTERDISCIPLINARY UNDERGRADUATE RESEARCH
OPEN ACCESS Citation: $\begin{aligned} & \text { Hammond-Thrasher, F. (2020) Medical Assistance in Dying: A } \\ & \text { Gendered Issue in Canada. Spectrum Issue No. } 6\end{aligned}$

doi: $10.29173 /$ spectrum93
Received: June 2, 2020

Accepted: Nov 11, 2020

Published: Nov 17, 2020 
nate with the values of individualism and choice $^{2}$ in Canadian liberal democratic society. In doing so, opponents of MAiD reproduce the same gender issues they claim to oppose and risk endangering women's access to MAiD in Canada.

The movement for MAiD in Canada arose out of an aging population, since the majority of baby boomers $^{3}$ are now seniors (65+), and a corresponding awareness of end-of-life issues. Canada's first palliative care hospice opened in 1975 in Montreal, offering holistic care and symptom management to make patients as comfortable as possible at the end of life. With more seniors in nursing homes and hospices, the patient rights movement demanded a more equal power dynamic between patients and physicians that would give patients a greater say in their treatment and, in the case of MAiD, the right to dying with dignity. Canada's legislation permits two types of MAiD: medically assisted suicide, where the patient takes a prescribed drug to end their life; and voluntary euthanasia, where the physician or nurse practitioner directly administers a drug that causes death, such as an injection. Both types require the patient's informed consent, having been informed of their medical diagnosis, treatment options, and alternatives to relieve suffering, such as palliative care (Government of Canada 2020a). The formulation of MAiD legislation is ongoing in Canada. In February 2020, the Attorney General introduced a bill to allow non-terminal Canadians to pursue MAiD "whether their natural death is reasonably foreseeable or not" (Government of Canada 2020b). Further debates include whether to allow MAiD for mature minors, patients with mental illness, and under advanced directives $^{4}$ (CCA 2018).

Opponents of MAiD have drawn from feminist discourse to identify women as a marginalized group made more vulnerable by MAiD legislation. Traditional arguments against MAiD stem from a "pro-life" perspective, which asserts the inherent value of human life or death by God's will. In contrast, supporters of MAiD often assert "pro-choice" arguments, based on the assessment of one's own quality of life and the human right to die. In Canada's increasingly secular society, pro-life advocates are often dismissed as ignorant, irrational, or superstitious and criticized for "imposing their religious dogma on others" (Canetto $2019,44)$. Bringing feminism into the picture allows opponents of MAiD to appeal to this secular, and thus supposedly rational, concept of choice by questioning women's ability to make the autonomous decision for MAiD within a patriarchal society. A preponderance of literature in the early 2000s, such as George's (2007) seminal piece, “A woman's choice? The gendered risks of voluntary euthanasia and physician assisted suicide," attempts to protect women from being victimized by MAiD legislation. Wong (2017) refers back to George's concept of gendered risks, casting MAiD as "the last of many non-choices" for women. Horgos' (2009) Lady Science article concludes by reaffirming not only women's right to life, but their right to quality of life: "Can we erase a woman's desire to die by offering her better mental health care? Can we dismantle a patriarchal system that leaves her with more options than death?" Based on a review of the literature on MAiD as a women's issue, I identify three discursive categories used to question women's autonomy in choosing MAiD: sociodemographic characteristics, gender roles, and power relationships. I caution that by co-opting feminist issues to further their argument against assisted dying, opponents of MAiD risk reifying - in other words, realizing - harmful gender roles, obscure women's lived experiences of health and healthcare, and overlook intersectional feminist issues related to the end of life.

\section{Sociodemographic Characteristics}

Pro-life arguments based on sociodemographic characteristics point out that conditions associated with being a woman - including a longer lifespan, greater chance of widowhood, higher incidence of depression and anxiety, and lesser socioeconomic resources may lead women to request MAiD more often than men. These arguments express concern that women will request MAiD because of their gender, rather than making a choice of their own "free" will. Firstly, on average, women have a longer lifespan than men. Wid- 
owhood tends to affect seniors, who represent 78\% of the people who accessed MAiD over a ten month period in 2018 (Government of Canada 2019). Since women in Canada live an average of four years Ionger than men, they are more likely to experience the death of their male partner. Widowhood, the argument goes, contributes to loneliness and depression, which may cloud women's pursuit of MAiD (Spitzer 2003; Wong 2017; King et al. 2019). However, Northcott and Wilson $(2017,180)$ caution against the tendency to over-problematize widowhood. For example, van den Hoonard's 1997 study found that, while the loss of the identity of "wife" is disorienting, most women described becoming "new woman" with positive characteristics such as increased independence (Northcott \& Wilson 2017, 181). A second study by van den Hoonard (2010) found that male widowers occupy a uniquely ambiguous social status: while a woman might be known as "John's widow" after her husband's death, a man is not known as "Jane's widower" after her death (Northcott \& Wilson 2017, 182). In fact, recent study by King and colleagues $(2019,1124)$ found that male widowers reported more depressive symptoms than women in relation to their loss. They attribute this difference to gender roles which cause men to be more vulnerable because a female partner is often their main source of emotional care and social connections (King et al. 2019,1124$)$.

According to Statistics Canada (2017), senior women are twice as likely as men to live alone. Further, women are three times more likely than men to experience depression and anxiety disorders, which contribute towards suicidal ideation and, potentially, a desire for a hastened death through MAiD (Solomon \& Noll 2008, 113). In Canada, having mental illness as a primary illness disqualifies you from accessing MAiD. However, this assumption overlooks the statistical distribution of MAiD in Canada. Canada reports that, of the patients who received MAiD in 2018, 51\% were men and $49 \%$ were women (Government of Canada 2019). This statistic differs from that of suicide, where women are more likely to attempt suicide but men are three times more likely than women to com- plete it (Government of Canada 2019). Opponents of MAiD highlight that MAiD equalizes suicide statistics, representing an increase in female deaths by suicide. However, it is important to note that suicide is not the same as MAiD. Patients who request MAiD are likely not suicidal or depressed. Rather, they are suffering from a grievous medical condition and wish for death with dignity. The key takeaway of the comparison of MAiD to suicide is that, although women suffer disproportionately from depression, they do not access MAiD at a greater rate than men in Canada.

Additionally, on average, women have less economic resources and family support than men (Solomon \& Noll 2008; Wong 2017; Canetto 2019), which may limit their access to care, especially given their longer lifespan. The above sociodemographic characteristics lend themselves to a simple and striking argument against women's autonomy in MAiD. However, this argument makes a radical assumption that the circumstances of old age and womanhood, such as poverty and loneliness, can be a stronger determinant of one's desire for a hastened death than one's health status itself. A 2015 study by de Jong Gierveld, a leading scholar in the study of loneliness, tested nine potential determinants of loneliness for seniors in Canada, including living conditions and social networks. Of the nine determinants, poor health was most strongly correlated to loneliness for seniors, suggesting that health plays a key role in later life. With an average score of 1.27 (where 0: not lonely and 6: extremely lonely), seniors were not very lonely at all, and, further, men were significantly lonelier than women (de Jong Gierveld et al. 2015, 131).

\section{Gender Roles}

Secondly, opponents of MAiD employ the discourse of women's gender roles, including caregiving, self-sacrifice, and fear of being a burden. The burden of caregiving falls disproportionately on women, who are expected to care for children and elderly relatives. Unfortunately, when this role reverses and women need care in later life, they often receive little to no care from husbands or family members (Canetto 2019, 42). 
While the burden of care seriously impacts the lives of women, opponents of MAiD draw on exaggerated versions of it, such as George's $(2007,22)$ statement that, "for some men, caregiving responsibilities are so overwhelming that they precipitate the homicide of female patients." This statement sensationalizes the burden of caregiving while failing to address or examine the experiences of women caregivers themselves (Spitzer 2003, 85). Discussions of women and MAiD highlight important concerns about women's health and healthcare which should be addressed by the medical system. However, opponents of MAiD explore gender to advance their arguments at the risk of reifying gender roles and misrepresenting women's lived experiences.

The case of Dr. Jack Kevorkian is often cited in discussions of women, gender roles, and MAiD. Kevorkian, an American pathologist, assisted in the deaths of approximately 130 patients in the ' 90 s before the legalization of physician-assisted dying and was tried repeatedly by the criminal justice system until his imprisonment in 1998. The discovery that two thirds of Kevorkian's patients were women alarmed the public (Solomon \& Noll 2008, 111). Opponents of MAiD have drawn upon gender roles to speculate if MAiD put "pressure on women to not be a burden to relatives...particularly those in their postreproductive years" (Solomon \& Nell 2008, 113) or, more absurdly, that MAiD was a "way to seek a relationship" (Wolf $1996,291)$ with Kevorkian. George $(2007,22)$ argues that a female "ethic of self-sacrifice" exists, demonstrated by a statement of a friend of one of Kevorkian's female patients: "She felt it was a gift to her family, sparing them the burden of taking care of her." By this same logic, the stereotype of suicide as a masculine and deviant action and the stigmatization of female suicides (Canetto 2019, 45) could lead to more men requesting MAiD because it aligns with stereotypical male gender roles. Scholars of gender roles make an important sociological point that debates about MAiD are "most often about a patient that doesn't exist-a patient with no gender, race, or insurance status" (Wolf 1996, 282). However, anti-MAiD arguments function similarly, drawing upon women's gender roles and overlooking men's gender roles to suit their arguments. Women's behaviour is certainly influenced by the social construction of gender. However, Foucault's (1978) influential quote, "where there is power, there is resistance," (95) reminds us that we must also consider the ways in which women resist gender roles. Canetto $(2019,46)$ notes that black women are excluded from hegemonic femininity ${ }^{5}$ ideals and, therefore, may reject them. Many life experiences and interlocking identities may lead women to reject gender roles and for the law to bar women's access to MAiD based on the existence of gender roles undermines this resistance.

\section{Power Relations}

Finally, opponents of MAiD co-opt discourses of power relations to highlight women's vulnerability within the medical system. Opponents of MAiD link domestic violence and mercy killings ${ }^{6}$ to MAiD. Wolf $(1996,292)$ asks the rhetorical question, "If a woman chooses to remain in a battering relationship, do we regard that as a choice to be respected and reason not to intervene?" She equates a woman's choice to stay in a violent relationship with choosing violence against herself through MAiD. However, this linkage assumes that MAiD is akin to violence when, in fact, it is often a personal choice to alleviate suffering. Wolf also assumes that the power dynamics of the relationship between a woman patient and a physician who is likely to be a man make it more likely for women to be approved for MAiD due to the valorization of female self-sacrifice and the sexist devaluation of women. However, Parks $(2000,32)$ argues that women's requests for MAiD are more likely to be denied because of the female ethic of self-sacrifice because "any self-interested and self-directed claims they make (in this case, the request to die) may be more easily discounted or dismissed as irrational" by male physicians. The tendency for dismissal of women's self-interested claims is demonstrated by the persistent dismissal of women's pain. A 2018 study by Mackey and Diercks (467) found that injured women are less likely than men to be directed to a trauma centre and experience greater lengths of time until 
treatment. Some opponents of MAiD worry that poor pain management will lead more women to request MAiD (Horgos 2019). However, acknowledging women's pain also requires that we consider MAiD as a valid option for women who, from their own bodily knowledge, consider their physical condition to be too painful to live with.

Women do not access MAiD more often than men in Canada and are less vulnerable to its legalization than pro-life advocates may suggest. However, a feminist analysis reveals that women play a gendered role in public advocacy for North America's MAiD movement. White women advocates such as Karen Ann Quinlan, Sue Rodriguez, Terri Schiavo, and Gloria Taylor dominated media reports and television screens during debates over MAiD legalization. Similarly, membership of the Hemlock Society, America's death with dignity organization, is $94 \%$ white and 63\% women (Canetto 2019, 40). George (2007) expresses concern that the overrepresentation of women in the fight for MAiD is because North American patriarchal society perceives women's deaths as right. Sikka (2019) and Canetto (2019) present a more nuanced theory that white women are the result of the "social and discursive construction of the model MAiD patient with idealized motivations" (Sikka, 2019, 17). Canetto summarizes why white women may advocate for MAiD:

White women have long, good-enough lives, it may be argued. If their life quality deteriorates when they are older, as related to illnesses and widowhood, and they have met or exceeded White male life expectancy, why stay? (Canetto 2019, 41).

Pursuing MAiD allows white women a supposedly noble, brave, and rational death: qualities white feminists have been fighting to be recognized for in movements such as women's suffrage. In contrast, black women are still focused on fighting for many basic rights and may not trust the medical system to support their autonomy in MAiD due to previous experiences of institutionalized racism (Canetto 2019, 46).
The feminist theory of intersectionality recognizes that social identities such as gender, race, and class are interlocking and, thus, give rise to unique forms of oppression. Analyzing MAiD with an intersectional lens can challenge misrepresentations of women's autonomy and refocus the debate on increasing access to MAiD for all eligible members of marginalized groups. Opponents of MAiD also co-opt the bodies of female MAiD advocates to further the discourses of women as victims of MAiD. Terri Schiavo was an American woman who entered a persistent vegetative state after a heart attack. Fifteen years later, in 2005, her husband and legal guardian won the right to have her feeding tube disconnected, paving the way for the right to die. An article called "Brian-damaged, not brain-dead" in the Christian Broadcasting Network photoshopped Schiavo's picture so that her wheelchair headrest out of her portrait (Eisen 2019). A picture in the Christian News Article shows Shiavo "appearing to smile and make deliberate eye contact with her mother under beatific lighting" (Eisen 2019), although she was in a persistent vegetative state and unable to display any emotions. These pictures deliberately portray Schiavo as a victim of MAiD legislation, rather than cardiac arrest. When women's experiences are considered not as a political technique but as a form of knowledge, they can be quite informative to future MAiD considerations. For example, Sikka revisits the concept of the burden of care to examine the emotional labour that women shoulder in attempting to conceal their emotions for others' benefit. The duty to manage emotions can be even stronger for women in ethnic communities as a result of more pronounced gender roles (Sikka 2019, 15). Further, she suggests that MAiD practitioners consider the ways in which gendered, racialized, trans, and disabled bodies "fit" or "misfit" within the traditional notions of unhealthiness which warrant MAiD (Sikka 2019, 16). The literature I reviewed in this paper revealed that men are more likely to be lonely in old age, when most Canadians access MAiD, and exhibit depressive symptoms due to widowerhood. Given that all people exist in gendered bodies, does this mean that everybody is vulnerable under MAiD legislation? An intersectional approach 
problematizes the idea that gender can be a sole determinant of the desire to live. Rather, characteristics such as race, sexuality, and dis/ability interact with one's gender identity, giving rise to unique vulnerabilities and strengths for white women, black men, queer trans people, and disabled non-binary people.

\section{Conclusion}

Opponents to MAiD worry that debates about MAiD are "most often about a patient that doesn't exist-a patient with no gender, race, or insurance status" (Wolf 1996, 282). Recognizing people as embedded in their social context contradicts liberal democratic individualism and "individual choice" discourse, including the right to die. However, I would argue that understanding individuals as social beings does not make MAiD unethical or impossible. A similarly heated ethical issue, abortion, is currently legal for women in Canada. Instead, recognizing individuals as social beings should lead us to research qualitative accounts of why different social groups choose to pursue MAiD. This research must consult directly with the people in question, acknowledging their embodied experience and knowledge. Secondly, an intersectional feminist approach calls for further research into the barriers to MAiD access that different groups face, such as Sikka's exploration of black women's distrust of the medical system due to histories of institutionalized racism. Finally, physicians and nurse practitioners should engage in debates and education about the social challenges facing patients of different social identities to inform their eligibility assessments and provisioning of MAiD. 


\section{Notes}

1. Quebec legalized medically assisted dying in 2015. However, only voluntary euthanasia (also known as clinician-administered MAiD) is permitted, and only physicians, not nurse practitioners, can administer MAiD.

2. Debates about whether women should have access to MAiD often appeal to the notion of "individual choice" that is popular in liberal democracy and mainstream feminism. In this paper, I argue that every individual's choices are influenced by society. Therefore, the fact that women tend to have lower socioeconomic conditions, strong pressure from gender roles, and lower status in power relations than men does not and should not mean that they cannot choose to request MAiD.

3. Baby boomers are the generation born after World War II, when there was a spike in the worldwide birth rate.

4. An advanced directive is a legal document which explains how someone would like medical decisions to be made about themselves if, in the future, they are deemed legally unfit to make decisions because of their health status.

5. Hegemonic femininity refers to the idealized characteristics of women's bodies and behaviours; for example, that women should be small and submissive. Hegemonic femininity overlaps with race, where white women's bodies are considered ideal.

6. Mercy killing refers to killing someone with the intent of relieving them from what the killer perceives as a painful or unlivable condition. 


\section{Works Cited}

Canetto, S.S. 2019. "If physician-assisted suicide is the modern woman's last powerful choice, why are white women its leading advocates and main users?" Professional Psychology: Research and Practice 50 (1): 39-50.

CCA (Council of Canadian Academics). 2018. "Summary of reports: State of knowledge on medical assistance in dying for mature minors, advance requests, and where a mental disorder is the sole underlying medical condition." Council of Canadian Academics.

de Jong Gierveld, J., Keating, N., and Fast, J.E. 2015. “Determinants of loneliness among older adults in Canada." Canadian Journal on Aging 34 (2): 125-136.

Eisen, E.X. 2019. “Do women have a right to die?” Lady Science. Retrieved in April, 2020 https://www.ladyscience.com/essays/do-women-have-a-right-to-die

Foucault, M. 1978. "The history of sexuality: Volume 1 an introduction." Pantheon Books: New York.

George, K. 2007. "A woman's choice? The gendered risks of voluntary euthanasia and physician-assisted suicide." Medical Law Review 15: 1-33.

Government of Canada. 2020a. "Medical Assistance in Dying." Government of Canada. Retrieved from https://www.canada.ca/en/health-canada/services/medical-assistance-dying.html

Government of Canada. 2020b. "Proposed changes to Canada's medical assistance in dying legislation." Department of Justice. Retrieved from https://www.justice.gc.ca/eng/csj-sjc/pl/ad-am/index.html

Government of Canada. 2019. "Fourth interim report on medical assistance in dying in Canada." Government of Canada. Retrieved from https://www.canada.ca/en/health-canada/services/publications/ health-system-services/medical-assistance-dying-interim-report-april-2019.html

Horgos, B. 2019. "Is physician-assisted suicide a feminist issue?" Lady Science. Retrieved from https:// www.ladyscience.com/ideas/physician-assisted-suicide-feminist-issue

King, B.M., Carr, D.C., and Taylor, M.G. 2019. "Depressive symptoms and the buffering effect of resilience on widowhood by gender." The Gerontologist 59 (6): 1122-1130.

Mackey, C., and Diercks, D.B. 2018. "Gender bias in the management of pain still exists." Society for Academic Emergency Medicine 25 (4): 465-469.

Northcott, H.C., and Wilson, D.M. 2017. Dying and Death in Canada. $3^{\text {rd }}$ ed. Toronto: University of Toronto Press.

Parks, J.A. 2000. "Why gender matters to the euthanasia debate." Hastings Centre Report (Jan-Feb): 30-36.

Sikka, T. 2019. "Barriers to access: A feminist analysis of medically assisted dying and the experience of marginalized groups." OMEGA Journal of Death and Dying 0 (0): 1-24.

Solomon, L.M., and Noll, R.C. 2008. Law, Ethics, Gender 5 (2): 110-114.

Spitzer, D.L. 2003. "Engendering health disparities." Canadian Journal of Public Health 96 (2): 78-96.

Wolf, S.M. 1996. "Gender, feminism, and death: Physician-assisted suicide and euthanasia." In Feminism and Bioethics, edited by S.M. Wolf, 282-317. New York: Oxford University Press.

Wong, R. 2017. "We need to address questions of gender in assisted dying." In The Conversation. Retrieved from https://theconversation.com/we-need-to-address-questions-of-gender-in-assisted-dying-85892 